\title{
Survival outcomes in unresectable metastatic rectal cancer patients after both primary site resection and chemoradiotherapy: a SEER-based observational study
}

\author{
Jianan Chen ${ }^{\#}$, Haipeng Chen ${ }^{\#}$, Fuqiang Zhao ${ }^{\#}$, Zheng Wang^, Qian Liu^ \\ Department of Colon and Rectal Surgery, National Cancer Center/National Clinical Research Center for Cancer/Cancer Hospital, Chinese \\ Academy of Medical Sciences and Peking Union Medical College, Beijing, China \\ Contributions: (I) Conception and design: J Chen, H Chen; (II) Administrative support: None; (III) Provision of study materials or patients: F Zhao; \\ (IV) Collection and assembly of data: J Chen, F Zhao; (V) Data analysis and interpretation: Z Wang, Q Liu; (VI) Manuscript writing: All authors; (VII) \\ Final approval of manuscript: All authors. \\ \#These authors contributed equally to this work. \\ Correspondence to: Zheng Wang; Qian Liu; Department of Colorectal Surgery, National Cancer Center/National Clinical Research Center for \\ Cancer/Cancer Hospital, Chinese Academy of Medical Sciences and Peking Union Medical College, No.17 Nanli, Panjiayuan, Beijing, China. \\ Email: 254846208@qq.com; liuqianncc@126.com.
}

Background: The liver is the most common site for rectal cancer metastasis, and liver resection combined with chemotherapy is the only treatment offering the possibility of long-term survival in patients with metastatic rectal cancer. However, a significant proportion of liver metastases cannot be surgically removed, and very limited data are available regarding the survival outcomes of these patients. This study aimed to investigate the survival pattern of rectal cancer patients with unresectable liver metastases after both chemoradiotherapy and primary tumor resection.

Methods: A total of 51,178 rectal cancer patients were identified from the Surveillance, Epidemiology, and End Results (SEER) database, of whom 448 had synchronous liver metastases and underwent both chemoradiotherapy and primary tumor resection. According to different treatment modalities, patients were divided into a hepatic resectable group and an unresectable group. The Kaplan-Meier method was used to estimate patient survival, and differences between the hepatic resectable and unresectable groups were compared using the log-rank test. Univariate and multivariate Cox regression models were used to analyze independent prognostic factors for unresectable tumors.

Results: Among the 448 metastatic rectal cancer patients, 60.3\% (270) had unresectable liver metastasis. The median survival period, 2-year overall survival (OS) rate, and 5-year OS rate of the unresectable group were 37.0 months, $68.5 \%$, and $32.9 \%$, respectively, compared with 56.0 months, $87.4 \%$, and $48.0 \%$, respectively, in the hepatic resectable group $(\mathrm{P}<0.001)$. Multivariate Cox regression analysis suggested that a poor or undifferentiated histological type was independently associated with poor CSS in patients with unresectable liver metastases $(\mathrm{P}=0.001)$.

Conclusions: Primary tumor resection combined with chemoradiotherapy might be able to yield a satisfactory survival outcome in unresectable metastatic rectal cancer patients. Resection of liver metastases remains the primary treatment for prolonging the OS and CSS time in stage IV patients.

Keywords: Rectal cancer; liver metastasis; primary tumor resection; prognosis; the surveillance, Epidemiology, and End results database (SEER)

^ ORCID: Jianan Chen, 0000-0002-6673-6884; Fuqiang Zhao, 0000-0003-0676-8371; Zheng Wang, 0000-0002-9021-7160; Qian Liu, 0000-0003-2510-3113. 
Submitted Jul 24, 2021. Accepted for publication Nov 28, 2021.

doi: $10.21037 /$ tcr-21-1399

View this article at: https://dx.doi.org/10.21037/tcr-21-1399

\section{Introduction}

Colorectal cancer (CRC) is a common malignancy of the digestive tract; according to Global Cancer Statistics, it ranks third in terms of incidence and second in terms of mortality (1). The development of distant metastatic disease is the main cause of death, and the liver is the most common site, followed by the lungs, peritoneal cavity, bone, and brain (2,3). Approximately $15-25 \%$ of all CRC patients present with liver metastases at the time of diagnosis, and almost $45-50 \%$ of patients develop liver metastases during the disease course $(4,5)$. Currently, radical resection is the standard treatment for metastatic CRC patients. Unfortunately, liver metastases are unresectable in up to $85 \%$ of patients initially (6). The median survival period in patients with untreated liver metastases is reported to be approximately eight months, and the 5 -year overall survival (OS) rate is less than $5 \%(7,8)$. Primary resection of liver metastases from CRC is potentially curative, with a 5 -year survival rate of $40-50 \%$ and a 10 -year survival rate of $20 \%(9,10)$.

Systemic chemotherapy represents the standard of care for metastatic patients, and it may result in the downstaging of metastases and the conversion of unresectable liver metastases to resectable metastases (9). Bismuth et al. (11) reported that neoadjuvant chemotherapy allows $15 \%$ of unresectable liver metastases to become resectable. However, liver metastases remain unresectable even after systemic therapy in most patients. According to the National Comprehensive Cancer Network (NCCN) guidelines, for synchronous unresectable metastases, the continuation of intensive chemotherapy (12) is recommended as the main therapeutic option, and other therapies include radiofrequency ablation therapy and molecular targeted therapy $(13,14)$.

Many studies have confirmed the potential curability of simultaneous or staged resection of liver metastases. However, the majority of rectal cancer metastases are unresectable, and there are limited published data to date on the survival outcomes of unresectable patients who have received intensive systemic chemoradiotherapy $(9,10)$. The primary aim of this study was to explore the survival outcomes of unresectable metastatic rectal cancer patients who had undergone systemic therapy and to identify risk factors that may affect prognosis. We present the following article in accordance with the STROBE reporting checklist (available at https://tcr. amegroups.com/article/view/10.21037/tcr-21-1399/rc).

\section{Methods}

\section{Data resources}

We extracted rectal cancer data from the SEER database. The SEER database contains demographics, incidence, and survival data from 18 population-based registries that represent approximately $28 \%$ of the US population. It is an open public database; all patient data are deidentified; therefore, written informed consent was not needed for this study. The study was conducted in accordance with the Declaration of Helsinki (as revised in 2013). Institutional ethical approval and informed consent were waived.

\section{Study population}

Initially, 51,178 rectal cancer patients diagnosed between January $1^{\text {st }}, 2010$, and December $31^{\text {st }}, 2015$, were identified using the SEER database. Tumor staging was performed according to the American Joint Committee on Cancer (AJCC) TNM staging system ( $7^{\text {th }}$ edition). We included only patients with liver metastases and patients who received chemotherapy, radiotherapy, and primary tumor resection. The surgical procedure of the primary tumor included two modalities: (I) partial proctectomy, such as low anterior resection, Hartmann's operation, and total mesorectal excision, and (II) total proctectomy (abdominoperineal resection). Patients who underwent local tumor excision or local tumor destruction were excluded. We restricted the radiation code to beam radiation (radiation sequence y before surgery, after surgery, or both) and excluded other radiation codes (refused, none/ unknown, radioactive implants, radioisotopes). In addition, we included only patients with tumor sequence numbers labeled "one primary only" and patients with Collaborative Stage (CS) Mets at diagnosis labeled "metastasis limited to a single distant organ" or "staged as M1a". After excluding 50,730 patients who were not eligible, 448 were included in 


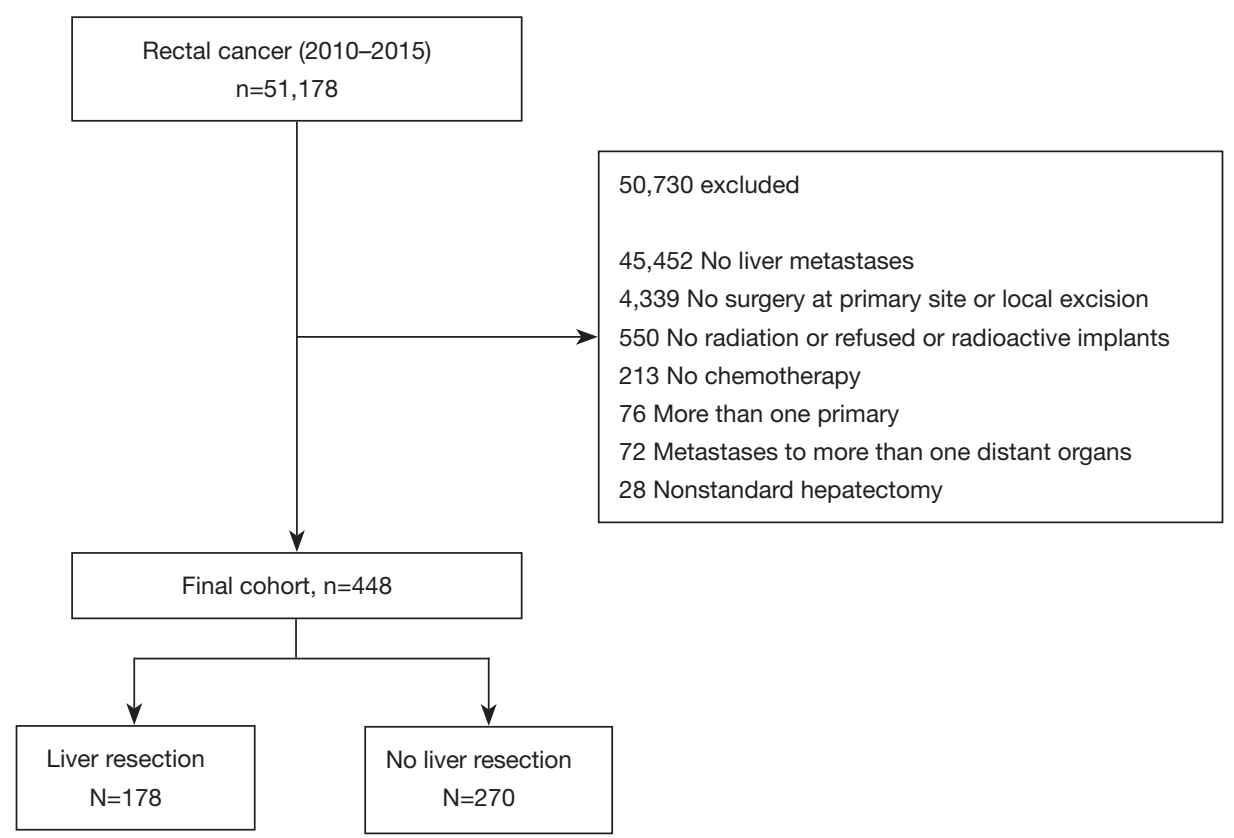

Figure 1 Flowchart of the inclusion and exclusion criteria.

this study. Patients were then stratified into two subgroups based on the treatment strategy of the liver metastases: (I) patients who received hepatic resection and (II) patients in whom hepatic resection was not performed (Figure 1). Other clinical characteristics, including sex, age, race, marital status, tumor grade, tumor size, AJCC T stage, and AJCC N stage, were also collected.

\section{Statistical analysis}

Baseline characteristics of the metastatic rectal cancer patients who had or had not undergone hepatic resection were compared using the chi-square test. Our primary outcomes were OS and cancer-specific survival (CSS). OS was defined as the time in months from diagnosis to either death or the last follow-up date, and CSS was defined as the time from the date of surgery to cancer-related death. The survival probability was estimated by the KaplanMeier method, and differences in survival between the two groups of patients were compared by using log-rank tests. Univariate and multivariate Cox regression models were used to identify prognostic factors in unresectable metastatic patients. The statistical analyses were performed using SPSS version 21.0 (IBM Corp., Armonk, NY, USA) and GraphPad Prism (version 8, GraphPad Prism Software Inc.).

\section{Results}

\section{Patient characteristics}

The demographic data of metastatic rectal cancer patients are shown in Table 1. The mean age at diagnosis was $60.39 \pm 11.59$ years. The majority of patients were male $(65.6 \%)$, white $(82.8 \%)$, and married $(60.7 \%)$. Most of the patients $(74.3 \%)$ had well or moderately differentiated tumors. Tumor size $\leq 5 \mathrm{~cm}$ was more frequent in patients (67.4\%). Among the 448 included patients, 401 (89.5\%) and $47(10.5 \%)$ were categorized as $\mathrm{T} 3 / \mathrm{T} 4$ and $\mathrm{T} 1 / \mathrm{T} 2$, respectively; $342(76.3 \%)$ and $106(23.7 \%)$ patients were categorized as N1/N2 and N0, respectively. Regarding the treatment, hepatic resection was performed in 178 (39.7\%) patients. Baseline characteristics are presented according to treatment modality in Table 2. There was no significant difference in sex, race, tumor grade, AJCC T stage, AJCC $\mathrm{N}$ stage, or marital status between the liver resectable group and the unresectable group. Liver resection was performed more often in patients aged $<60$ years $(66.3 \%$ vs. $54.8 \%$, $\mathrm{P}=0.016)$ and with a primary tumor size $>5 \mathrm{~cm}(39.3 \%$ vs. $28.1 \%, \mathrm{P}=0.014)$.

\section{Patient survival}

Kaplan-Meier curves for the OS and CSS of metastatic 
Table 1 Baseline characteristics of unresectable metastatic rectal cancer patients $(\mathrm{n}=448)$

\begin{tabular}{|c|c|}
\hline Characteristics & Number of patients, $\mathrm{n}(\%)$ \\
\hline \multicolumn{2}{|c|}{ Age at diagnosis, years, no. (\%) } \\
\hline Mean \pm SD & $60.39 \pm 11.59$ \\
\hline$<60$ & $266(59.4)$ \\
\hline$\geq 60$ & $182(40.6)$ \\
\hline \multicolumn{2}{|l|}{ Sex, no. (\%) } \\
\hline Male & $294(65.6)$ \\
\hline Female & $154(34.4)$ \\
\hline \multicolumn{2}{|l|}{ Race, no. (\%) } \\
\hline White & $371(82.8)$ \\
\hline Black & $32(7.1)$ \\
\hline Others & $45(10.0)$ \\
\hline \multicolumn{2}{|l|}{ Marital status, no. (\%) } \\
\hline Married & $272(60.7)$ \\
\hline Unmarried & $154(34.4)$ \\
\hline Unknown & $22(4.9)$ \\
\hline \multicolumn{2}{|l|}{ Tumor grade, no. (\%) } \\
\hline Poor + undifferentiated & $66(14.7)$ \\
\hline Well + moderately & $333(74.3)$ \\
\hline Unknown & $49(10.9)$ \\
\hline \multicolumn{2}{|l|}{ Tumor size, cm, no. (\%) } \\
\hline $0-5 \mathrm{~cm}$ & $302(67.4)$ \\
\hline$>5 \mathrm{~cm}$ & $146(32.6)$ \\
\hline \multicolumn{2}{|l|}{ AJCC T stage, no. (\%) } \\
\hline $\mathrm{T} 1 / \mathrm{T} 2$ & $47(10.5)$ \\
\hline $\mathrm{T} 3 / \mathrm{T} 4$ & $401(89.5)$ \\
\hline \multicolumn{2}{|l|}{ AJCC N stage, no. (\%) } \\
\hline NO & $106(23.7)$ \\
\hline N1/N2 & $342(76.3)$ \\
\hline \multicolumn{2}{|l|}{ Treatment modality, no. (\%) } \\
\hline Hepatic resection & $178(39.7)$ \\
\hline Non-resection & $270(60.3)$ \\
\hline
\end{tabular}

SD, standard deviation; AJCC, American Joint Committee on Cancer. rectal cancer patients are shown in Figure 2. The mean survival periods and 2- and 5-year OS rates of metastatic rectal cancer patients after both chemoradiotherapy and primary tumor resection are shown in Table 3. The median OS periods of the liver resectable patients and liver unresectable patients were 56.0 and 37.0 months, and the 5 -year OS rates were $48.0 \%$ and $32.9 \%$, respectively.

Subgroup univariate and multivariate Cox regression analyses were used to explore the risk factors for survival in unresectable metastatic rectal cancer patients. Univariate Cox regression analysis showed that male sex and poor or undifferentiated tumors were independent predictors of OS (HR, 1.332, 95\% CI: 1.104-1.560, $\mathrm{P}=0.003$; HR, 2.045; 95\% CI: $1.370-3.055$; $\mathrm{P}<0.001)$. Furthermore, in the multivariable Cox regression analysis, male sex (HR, 1.781; 95\% CI: 1.190-2.373; $\mathrm{P}=0.003$ ), an unmarried status (HR, 1.521; 95\% CI: $1.055-2.193 ; \mathrm{P}=0.025$ ), and poor or undifferentiated tumors (HR, 2.059; 95\% CI: 1.346-3.149; $\mathrm{P}=0.001)$ were confirmed to be independent risk factors for a poor prognosis (Table 4). The results of univariate and multivariate Cox regression analysis for cancerspecific survival of liver unresectable patients are described in Table 5. The Multivatiate Cox regression analysis suggested that a poor or undifferentiated histological type were independently associated with poor CSS in patients with unresectable liver metastases.

\section{Discussion}

CRC with liver metastases is a significant clinical problem. Fifteen percent to $25 \%$ of CRC patients present with synchronous liver metastases at the time of diagnosis, and in up to $85 \%$ of these patients, metastatic lesions cannot be surgically resected $(5,6)$. Hepatic resection combined with chemotherapy is the standard treatment for metastatic rectal cancer patients and can lead to a 5-year OS rate of $40-50 \%$ (9). In our study, the 2- and 5-year OS rates in patients who underwent hepatic resection were $73.0 \%$ and $48.0 \%$.

For unresectable metastatic patients, whether resection of the primary tumor affords a survival advantage remains controversial. According to the NCCN guidelines, if the primary tumor is not acutely obstructed, palliative resection of the primary tumor is rarely recommended 
Table 2 Baseline characteristics of Group A (liver resectable) and B (liver unresectable)

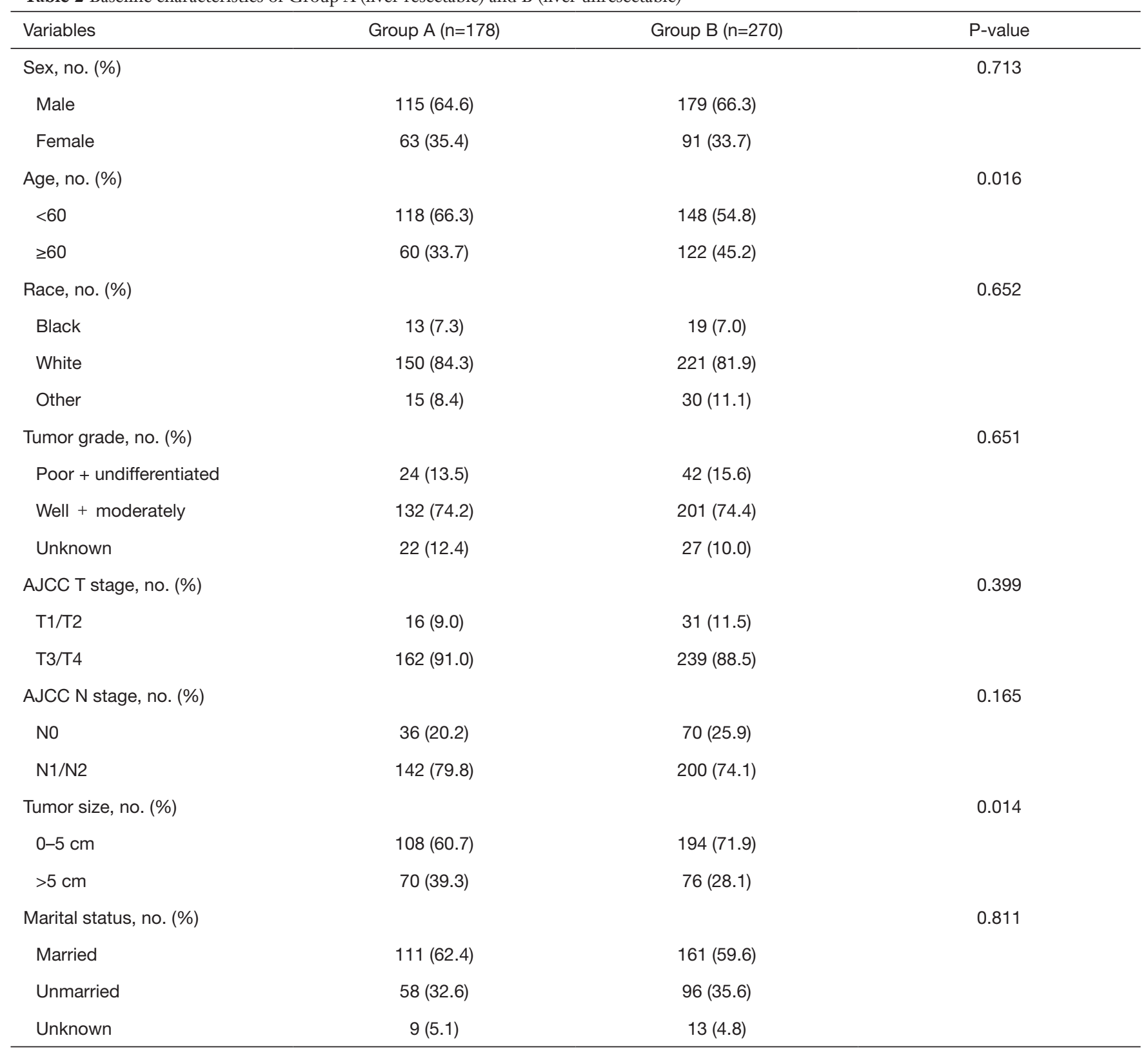

AJCC, American Joint Committee on Cancer.

because incomplete resection of the tumor (R1/R2 resection) has not shown a survival benefit (15). However, two registry studies in the United States suggested that nearly $70 \%$ of metastatic CRC patients have undergone resection of the primary tumor, and both studies reported a significant survival advantage $(16,17)$. Faron et al. (18) also reported the outcomes of 810 CRC patients with unresectable synchronous metastases; $59 \% \quad(n=478)$ underwent resection of the primary tumor. Compared with patients in the nonprimary tumor resection group, those in the resection group were more likely to have lower baseline carcinoembryonic antigen (CEA) and alkaline phosphatase levels, and primary tumor resection was independently associated with better OS and PFS. The median survival periods of the primary tumor resection group and nonprimary tumor resection group were 19.2 months and 13.3 months $(\mathrm{P}<0.001)$, respectively (18). In clinical research, there are limited data 
A

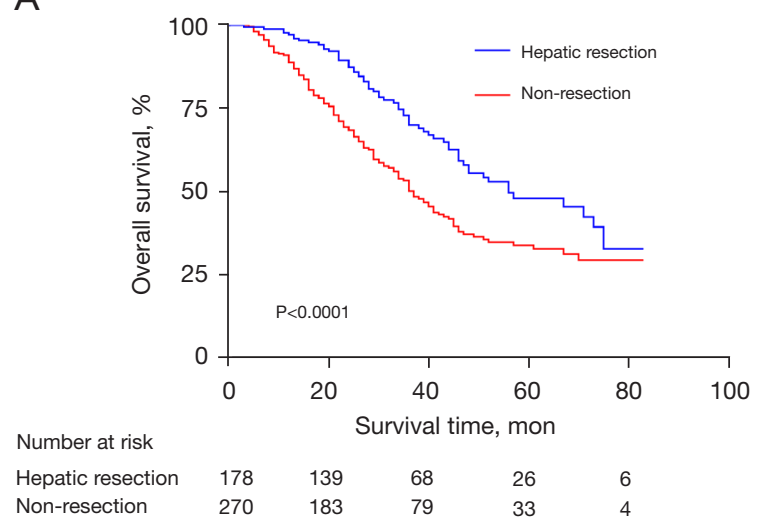

B

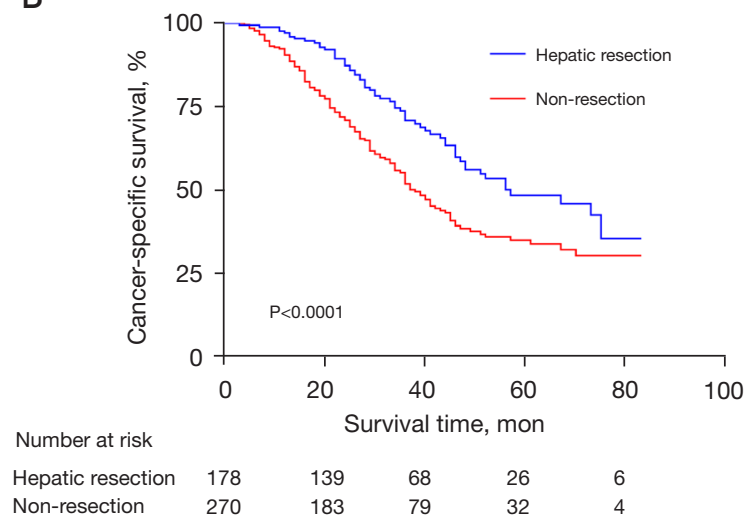

Figure 2 OS (A) and CSS (B) estimated with the Kaplan-Meier methods for metastatic rectal cancer patients. OS, overall survival; CSS, cancer-specific survival.

Table 3 Mean survival and 2-, 5-year OS of metastatic rectal cancer patients (n=448)

\begin{tabular}{lccc}
\hline Variables & Mean survival (mons) & 2-year OS & 5-year OS \\
\hline Liver resectable & 56.0 & 0.874 & 0.480 \\
Liver unresectable & 37.0 & 0.685 & 0.329 \\
\hline
\end{tabular}

OS, overall survival.

regarding the survival pattern of unresectable metastatic patients who have undergone both primary tumor resection and systemic therapy. Our study suggests a satisfactory survival outcome in these patients, with a median survival period of 37.0 months and a 5 -year OS rate of $32.9 \%$. Compared to the reported primary tumor resection rate of $70 \%$ in metastatic CRC patients, in our study, $24.2 \%$ of metastatic rectal cancer patients underwent surgery at the primary site (Figure 1). The main reasons for this difference may be that rectal surgery frequently requires a diverting stoma, and abdominoperineal resection has to be performed for patients with low rectal cancer, making neither surgeons nor patients willing to accept surgery as a preferred treatment method.

Compared with other studies $(19,20)$, the OS rates of the unresectable metastatic rectal cancer patients in our study were satisfactory. After comparing the inclusion criteria of our study to those of others, we believe that the main difference is that we added radiotherapy to our inclusion criteria, and constantly updated chemotherapy and radiotherapy have played significant roles in the improvement of survival outcomes. Recently, total neoadjuvant therapy (TNT) approach is increasingly being utilized in clinical practice. The TNT approach, which means induction or consolidation chemotherapy with chemoradiotherapy prior to surgery, was first used in patients with locally advanced rectal cancer $\mathrm{p}(\mathrm{T} 3 / 4, \mathrm{~N} 0$, or node positive). According to a large study conducted at the Memorial Sloan Kettering Cancer Center, the complete response (CR) rate in advanced rectal cancer patients was $36 \%$ in the TNT group and $21 \%$ in the chemoradiotherapy with planned adjuvant chemotherapy group. They also noted that patients who received TNT were more likely to complete the planned chemotherapy regiment with less dose reductions. Several advantages of the TNT approach have also been pointed out by some other relevant studies: the improved delivery of planned therapy, increased downstaging, and the in vivo assessment of chemosensitivity $(21,22)$.

In our study, we also used univariate and multivariate Cox regression models to analyze the survival of unresectable metastatic rectal cancer patients. We found that poor or undifferentiated tumors, which accounted for $14.7 \%$ of all malignant neoplasms, were the strongest risk factor associated with a poor prognosis, consistent with previous reports $(23,24)$; this might be because poor or undifferentiated cancer cells display reduced cohesiveness and have a stronger ability to invade surrounding tissues 
Table 4 Subgroup univariate and multivariate Cox regression analyses for OS of liver unresectable patients $(\mathrm{n}=270)$

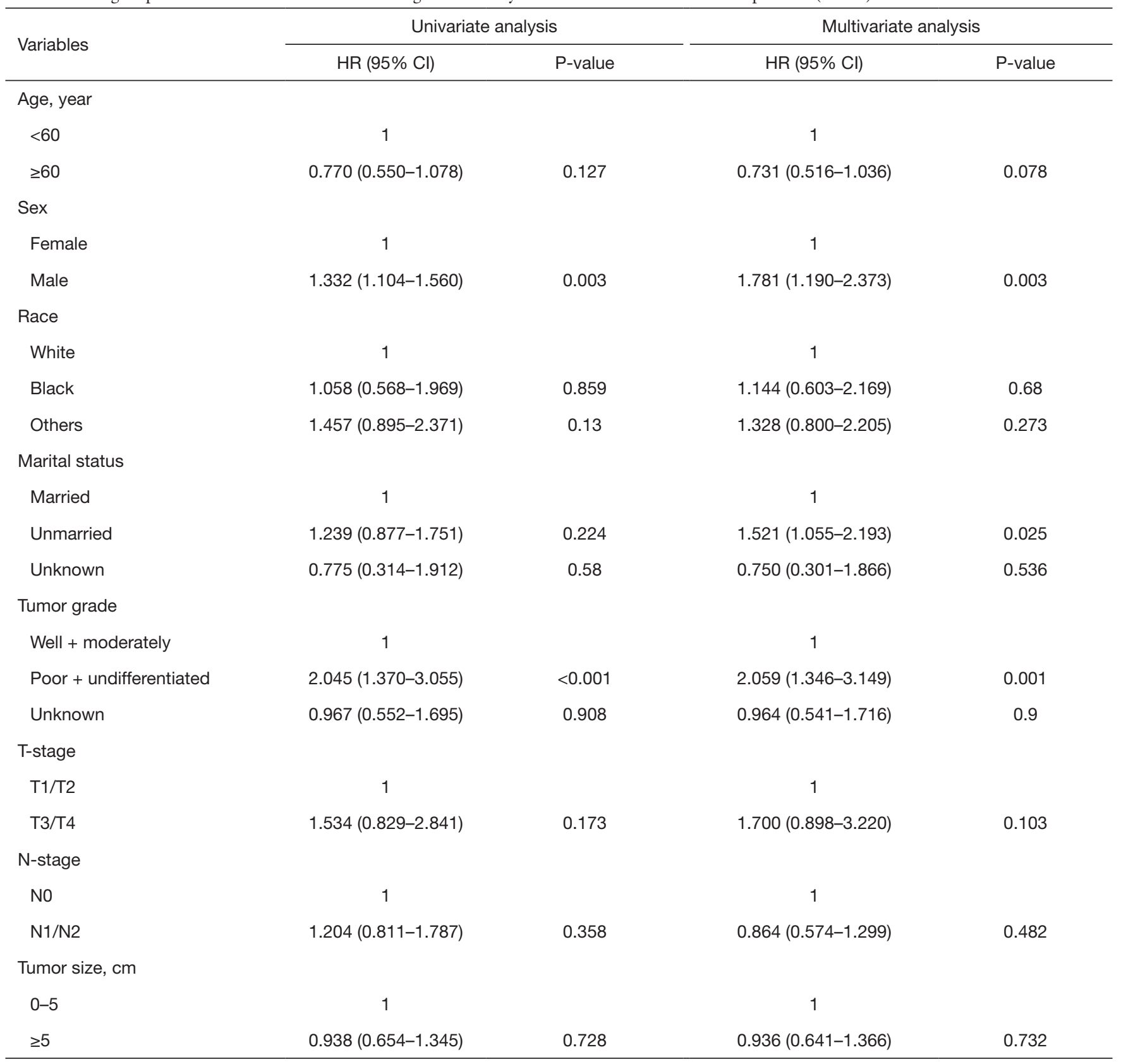

OS, overall survival.

and are more likely to metastasize to distant organs. Cox regression analysis also indicated that male sex was associated with a poor prognosis in stage IV patients. Several studies have shown that women are less likely to develop CRC than men, and women with CRC have a longer survival time than men $(25,26)$. One explanation for the sex differences lies in circulating androgens, which will decrease the effectiveness of chemotherapy through the TUBB3 pathway in males (27). We also found that married patients had a better prognosis than unmarried patients, and some studies have indicated that psychosocial support is the reason for better survival (28).

One of the greatest strengths of the present study is the large sample size provided by the SEER database; however, 
Table 5 Subgroup univariate and multivariate Cox regression analyses for CSS of liver unresectable patients $(\mathrm{n}=270)$

\begin{tabular}{|c|c|c|c|c|}
\hline Variables & \multicolumn{2}{|c|}{ Univariate analysis } & \multicolumn{2}{|c|}{ Multivariate analysis } \\
\hline \multicolumn{5}{|l|}{ Age, year } \\
\hline$<60$ & 1 & & 1 & \\
\hline$\geq 60$ & $0.824(0.655-1.126)$ & 0.110 & $0.646(0.365-1.024)$ & 0.058 \\
\hline Female & 1 & & 1 & \\
\hline Male & $1.483(1.116-1.705)$ & 0.016 & $0.763(0.390-1.254)$ & 0.083 \\
\hline \multicolumn{5}{|l|}{ Race } \\
\hline White & 1 & & 1 & \\
\hline \multicolumn{5}{|l|}{ Marital status } \\
\hline Married & 1 & & 1 & \\
\hline Unmarried & $1.325(0.863-1.639)$ & 0.252 & $1.471(1.173-2.218)$ & 0.066 \\
\hline Unknown & $0.733(0.332-1.875)$ & 0.472 & $0.679(0.366-1.975)$ & 0.373 \\
\hline \multicolumn{5}{|l|}{ Tumor grade } \\
\hline Well + moderately & 1 & & 1 & \\
\hline Poor + undifferentiated & $2.292(1.284-3.519)$ & $<0.001$ & $2.402(1.304-3.295)$ & 0.001 \\
\hline Unknown & $0.870(0.492-1.339)$ & 0.908 & $0.997(0.285-1.916)$ & 0.840 \\
\hline $\mathrm{N} 1 / \mathrm{N} 2$ & $1.228(0.821-1.942)$ & 0.362 & $0.404(0.274-1.199)$ & 0.325 \\
\hline \multicolumn{5}{|l|}{ Tumor size, cm } \\
\hline $0-5$ & 1 & & 1 & \\
\hline$\geq 5$ & $0.946(0.534-1.435)$ & 0.629 & $0.749(0.441-1.429)$ & 0.647 \\
\hline
\end{tabular}

CSS, cancer-specific survival.

as a retrospective database, it has several limitations. First, the SEER database lacks some key clinical information that might be important for prognosis, such as tumor markers, the margin of resection, and postoperative complications and due to its retrospective nature, there may be selection bias in our study, a multicenter prospective research is needed to confirm these results. Second, the SEER database does not provide detailed information about chemoradiotherapy regimens, biological targeted therapy, CEA level, Kras, which could also influence prognosis. Third, it is not possible to distinguish between patients with isolated hepatic metastasis or multiple hepatic metastases, and there is little information about the treatment strategies for liver metastasis, which may also affect patient prognosis. 
In conclusion, our results show that after chemoradiotherapy and primary tumor resection, the median survival period and 2-, and 5-year OS rates in unresectable metastatic rectal cancer patients were 37.0 months, $68.5 \%$, and $32.9 \%$, respectively. A poor or undifferentiated tumor is the strongest risk factor associated with poor survival outcomes.

\section{Acknowledgments}

Funding: This work was supported by the National Key Research and Development Program of China "Major chronic non-communicable disease prevention and control research" (No. 2019YFC1315705) and the Beijing Marathon of Hope, Cancer Foundation of China (No. LC2017L07).

\section{Footnote}

Reporting Checklist: The authors have completed the STROBE reporting checklist. Available at https://tcr. amegroups.com/article/view/10.21037/tcr-21-1399/rc

Conflicts of Interest: All authors have completed the ICMJE uniform disclosure form (available at https://tcr.amegroups. com/article/view/10.21037/tcr-21-1399/coif). The authors have no conflicts of interest to declare.

Ethical Statement: The authors are accountable for all aspects of the work in ensuring that questions related to the accuracy or integrity of any part of the work are appropriately investigated and resolved. The study was conducted in accordance with the Declaration of Helsinki (as revised in 2013).

Open Access Statement: This is an Open Access article distributed in accordance with the Creative Commons Attribution-NonCommercial-NoDerivs 4.0 International License (CC BY-NC-ND 4.0), which permits the noncommercial replication and distribution of the article with the strict proviso that no changes or edits are made and the original work is properly cited (including links to both the formal publication through the relevant DOI and the license). See: https://creativecommons.org/licenses/by-nc-nd/4.0/.

\section{References}

1. Bray F, Ferlay J, Soerjomataram I, et al. Global cancer statistics 2018: GLOBOCAN estimates of incidence and mortality worldwide for 36 cancers in 185 countries. CA Cancer J Clin 2018;68:394-424.

2. Engstrand J, Nilsson H, Strömberg C, et al. Colorectal cancer liver metastases - a population-based study on incidence, management and survival. BMC Cancer 2018;18:78.

3. Guan X, Ma CX, Quan JC, et al. A clinical model to predict the risk of synchronous bone metastasis in newly diagnosed colorectal cancer: a population-based study. BMC Cancer 2019;19:704.

4. Manfredi S, Lepage C, Hatem C, et al. Epidemiology and management of liver metastases from colorectal cancer. Ann Surg 2006;244:254-9.

5. Van Cutsem E, Nordlinger B, Cervantes A. Advanced colorectal cancer: ESMO clinical practice guidelines for treatment. Ann Oncol 2010;21:v93-7.

6. Zervoudakis A, Boucher T, Kemeny NE. Treatment options in colorectal liver metastases: hepatic arterial infusion. Visc Med 2017;33:47-53.

7. Petrelli NJ, Abbruzzese J, Mansfield P, et al. Hepatic resection: the last surgical frontier for colorectal cancer. J Clin Oncol 2005;23:4475-7.

8. House MG, Ito H, Gönen M, et al. Survival after hepatic resection for metastatic colorectal cancer: trends in outcomes for 1,600 patients during two decades at a single institution. J Am Coll Surg 2010;210:744-52, 752-5.

9. Kemeny NE, Melendez FD, Capanu M, et al. Conversion to resectability using hepatic artery infusion plus systemic chemotherapy for the treatment of unresectable liver metastases from colorectal carcinoma. J Clin Oncol 2009;27:3465-71.

10. Park MS, Yi NJ, Son SY, et al. Histopathologic factors affecting tumor recurrence after hepatic resection in colorectal liver metastases. Ann Surg Treat Res 2014;87:14-21.

11. Bismuth H, Adam R, Lévi F, et al. Resection of nonresectable liver metastases from colorectal cancer after neoadjuvant chemotherapy. Ann Surg 1996;224:509-20; discussion 520-2.

12. Van Cutsem E, Danielewicz I, Saunders MP, et al. Trifluridine/tipiracil plus bevacizumab in patients with untreated metastatic colorectal cancer ineligible for intensive therapy: the randomized TASCO1 study. Ann Oncol 2020;31:1160-8.

13. Benson AB, Venook AP, Al-Hawary MM, et al. Rectal cancer, version 2.2018, NCCN clinical practice guidelines in oncology. J Natl Compr Canc Netw 2018;16:874-901. 
14. Van Cutsem E, Cervantes A, Nordlinger B, Arnold D; ESMO Guidelines Working Group. Metastatic colorectal cancer: ESMO Clinical Practice Guidelines for diagnosis, treatment and follow-up. Ann Oncol 2014;25 Suppl 3:iii19. Erratum in: Ann Oncol 2015;26 Suppl 5:v174-7.

15. Altendorf-Hofmann A, Scheele J. A critical review of the major indicators of prognosis after resection of hepatic metastases from colorectal carcinoma. Surg Oncol Clin N Am 2003;12:165-92, xi.

16. Temple LK, Hsieh L, Wong WD, et al. Use of surgery among elderly patients with stage IV colorectal cancer. J Clin Oncol 2004;22:3475-84.

17. Cook AD, Single R, McCahill LE. Surgical resection of primary tumors in patients who present with stage IV colorectal cancer: an analysis of surveillance, epidemiology, and end results data, 1988 to 2000. Ann Surg Oncol 2005;12:637-45.

18. Faron M, Pignon JP, Malka D, et al. Is primary tumour resection associated with survival improvement in patients with colorectal cancer and unresectable synchronous metastases? A pooled analysis of individual data from four randomised trials. Eur J Cancer 2015;51:166-76.

19. Chen HH, Lin JK, Chen JB, et al. Neoadjuvant therapy of bevacizumab in combination with oxaliplatin and capecitabine (XELOX) for patients with metastatic colorectal cancer with unresectable liver metastases: a phase II, open-label, single-arm, noncomparative trial. Asia Pac J Clin Oncol 2018;14:61-8.

20. Nozawa H, Ishihara S, Kawai K, et al. Conversion to resection in patients receiving systemic chemotherapy for unresectable and/or metastatic colorectal cancer-

Cite this article as: Chen $\mathrm{J}$, Chen $\mathrm{H}$, Zhao F, Wang Z, Liu Q. Survival outcomes in unresectable metastatic rectal cancer patients after both primary site resection and chemoradiotherapy: a SEER-based observational study. Transl Cancer Res 2022;11(1):171-180. doi: 10.21037/tcr-21-1399 predictive factors and prognosis. Clin Colorectal Cancer 2018;17:e91-7.

21. Chau I, Brown G, Cunningham D, et al. Neoadjuvant capecitabine and oxaliplatin followed by synchronous chemoradiation and total mesorectal excision in magnetic resonance imaging-defined poor-risk rectal cancer. J Clin Oncol 2006;24:668-74.

22. Cercek A, Goodman KA, Hajj C, et al. Neoadjuvant chemotherapy first, followed by chemoradiation and then surgery, in the management of locally advanced rectal cancer. J Natl Compr Canc Netw 2014;12:513-9.

23. Fonseca GM, de Mello ES, Faraj SF, et al. Prognostic significance of poorly differentiated clusters and tumor budding in colorectal liver metastases. J Surg Oncol 2018;117:1364-75.

24. Johncilla M, Chen Z, Sweeney J, et al. Tumor grade is prognostically relevant among mismatch repair deficient colorectal carcinomas. Am J Surg Pathol 2018;42:1686-92.

25. Anderin C, Martling A, Hellborg H, et al. A populationbased study on outcome in relation to the type of resection in low rectal cancer. Dis Colon Rectum 2010;53:753-60.

26. Lydrup ML, Höglund P. Gender aspects of survival after surgical treatment for rectal cancer. Colorectal Dis 2015;17:390-6.

27. Mariani M, Zannoni GF, Sioletic S, et al. Gender influences the class III and V $\beta$-tubulin ability to predict poor outcome in colorectal cancer. Clin Cancer Res 2012;18:2964-75.

28. Beattie S, Lebel S, Tay J. The influence of social support on hematopoietic stem cell transplantation survival: a systematic review of literature. PLoS One 2013;8:e61586. 